\title{
WACANA MELEGALKAN LGBT DI INDONESIA (STUDI ANALISIS LGBT DALAM PERSPEKTIF HAM DAN PANCASILA)
}

\author{
MISKARI \\ Dosen Fakultas Syariah Program Studi Ahwal Syakhsiyah \\ Sekolah Tinggi Agama Islam Swasta (STAIS) Mempawah \\ Mahatthoh@gmail.com
}

\begin{abstract}
Abstrack
Lesbian, gay, bisexual and transgender phenomenon is one of the alternative lifestyle that spreads in Indonesia which is experienced by teenagers. It creates new problem for teenagers, their family, and their surroundings. The biggest problem in this case is there's no specific step for counselor and psychidrist to help transgender, gay, or lesbian counselee. This article deals with the new issue of homosexuality from the perspective of human rights international law (HAM) and Pancasila. The result of understanding towards human rights international law as well as towards Indonesia law (Pancasila) as the blessings for the universe places buman beings in the most respected position. However there emerge the phenomenon of non-mainstream sexual orientation, such as lesbian, gay, bisexual and transgender (LGBT) which is believed part of propaganda of buman rights. The fundamental principle of the concept of state law is rule by law is not rule by man, which means that the law was intended implies enforcement of recognition, equality, individual freedom, and buman rights. But in Indonesia has the concept of a state of law that has the characteristics of Pancasila, because Pancasila is Staats fundamental norm for Indonesia, so that the implementation of the concept of state of law in Indonesia should be underlying by moral principle from precepts of the Pancasila, and therefore theauthor tried to look at the characteristics of the concept of state law Pancasila. Even if these laws are loosely enforced, their mere existence translates into legal and societal stigmatization by branding LGBT people as immoral. In asence, Indonesia need to present frontline in keep identity his people and do not terikut current globalization who break the identity of we, then the it must be remembered our country legal state and also crusader for human rights was one understand liberalism being without batas.oleh therefore, let us back at the identity g, back to of philosophy pancasila and the constitution of 1945 by means of infuse religious values and culture sublime. then, Pancasila wïl reject $L G B T$.
\end{abstract}

Keywords: LGBT, Human Rights, Pancasila.

\section{PENDAHULUAN}

Fenomena agama dan sosial yang sedang heboh dibincangkan saat ini adalah lesbian, gay, bisexual, transgender yang kemudian disingkat (LGBT). LGBT merupakan salah satu orientasi seksual yang dianggap abnormal di dalam masyarakat Indonesia, karena tidak sesuai dengan peraturan dan nilai-nilai yang berada dalam masyarakat. LGBT bisa dialami oleh siapa saja, tidak terkecuali pada remaja. Pada usia remaja, banyak dari mereka yang tidak mengetahui identitas seksualnya, banyak pula dari mereka yang hanya mencoba-coba ataupun memang sengaja melakukan sehingga mereka mengalami orientasi seksual yang di anggap abnormal ini. Pada masamasa itulah mereka mencari-cari identitas seksualnya. Seksualitas pada dasarnya merupakan landasan kehidupan sosial yang seringkali lebih menentukan ketimbang sejarah raja-raja, sejarah politik, atau peristiwa-peristiwa besar yang telah kita kenal selama ini. Sistem seksualitas dimasukkan ke dalam satu bejana dengan konstruksi gender. Artinya, tafsir atas seksualitas merujuk pada konstruksi gender di dalam masyarakat. Laki-laki dikonstruksikan sebagai sosok yang

44 RAHEEMA: J urnal Studi Gender dan Anak 
maskulin, sedangkan perempuan sebagai sosok yang feminin. Serangkaian konstruksi inilah, yang melatarbelakangi pembentukan identitas seksual antara laki-laki dan perempuan.

Penomena LGBT muncul pada tahun sekitar 2012 bahkan sudah ada 10 negara yang telah melegalkan pernikahan sesama jenis, yaitu Belanda, Belgia, Spanyol, Portugal, Swedia, Norwegia, Islandia, Canada, Argentina, dan Afrika Selatan. Sedang di Indonesia sendiri tampaknya legalisasi pernikahan sesama jenis masih sangat sulit direalisasikan.Walaupun demikian, terbukti perjuangan kelompok LGBT untuk dapat menikah tetap ada. Salah satu faktanya adalah tahun 1981 Indonesia dihebohkan oleh terungkapnya ,pernikahan antara Jossie dan Bonie, yang merupakan pasangan lesbian. Pernikahan mereka dilaksanakan pada tanggal 6 Juli 1981 di sebuah Cafee di Jakarta Selain Jossie dan Bonnie, ada pasangan Wim dan Phillip yang „menikah di Yogyakarta. Wim dan Philip adalah pasangan gay pertama di Indonesia yang melegalkan hubungan mereka dalam sebuah pernikahan.

Lalu, bagaimana pandangan HAM dan 'Pancasila serta UUD 45 terhadap penomena LGBT’? Dan bagaimana pandangan hukum agama-agama resmi Indonesia terhadap LGBT yang ada di Indonesia??

\section{PEMBAHASAN}

\section{LGBT dan Indonesia}

Pada dasarnya, secara fitrah, manusia diciptakan oleh Allah swt berikut dengan dorongan jasmani dan nalurinya. Salah satu dorongan nalurinya adalah naluri melestarikan keturunan (gharizatu al na'u/bibdhun na:') yang diantara manifestasinya adalah rasa cinta dan dorongan seksual antara lawan jenis (pria dan wanita). Pandangan pria terhadap wanita begitupun wanita terhadap pria adalah pandangan untuk melestarikan keturunan (Hifdzun Nash) bukan pandangan pemuasan nafsu semata. Begitu juga, tujuan diciptakan naluri ini adalah untuk melestarikan keturunan sedang pelestarian keturunan ini hanya bisa dilakukan oleh pasangan suami istri (lakilaki dan perempuan). Ini semakna dengan definisi nikah, adalah unit terkecil dalam masyarakat yang terdiri dari suami dan istri, atau suami istri dan anak-anaknya. Seiring dengan berkembangnya zaman, mulai banyak bentuk keluarga yang tadinya tidak dianggap keluarga kini disebut sebagai keluarga menurut Badan Kependudukan dan Keluarga Berencana Nasional atau disingkat BKKBN (2011).

Perkawinan atau pernikahan dalam Islam hanya boleh dilakukan oleh mempelai yang berjenis kelamin seksual laki-laki dan perempuan. Ketentuan hukum ini dianggap sebagai ketentuan yang ma'lumun min ad-din bi ad-dharurat atau ketentuan hukum yang mujma' alaih (kesepakatan bersama) ${ }^{1}$. Dalam UU pun diartikan bahwa pernikahan heteroseksual di Indonesia, suami atau laki-laki, memegang peran sebagai kepala keluarga, sedangkan Istri, atau perempuan, akan memegang peran sebagai ibu rumah tangga. Hal ini didukung oleh UU No. 1 Tahun 1974 Pasal 31 ayat (3) yang mengatakan "Suami adalah kepala keluarga dan Istri adalah Ibu ruma tangga". Dengan demikian, keluarga itu dihuni oleh laki-laki dan perempuan. Buka laki-laki sesama laki-laki atau perempuan sesama perempuan.

Al-Quran menjelaskan:

"Dan jika kamu takut tidak akan dapat berlaku adil terhadap (hak-hak) perempuan yang yatim (bilamana kamu mengawininya), maka kawinilah wanita-wanita (lain) yang kamu senangi : dua-dua, tiga-tiga atau empatempat. Namun jika kamu takut tidak akan dapat berbaku adil, maka

${ }^{1}$ Imam Nakhe'I, LGBT PERPSPEKTIF ISLAM. (Jurnal Lisan Al-Hal Volume 4, No. 2, Desember, 2012) hlm, 6 . 
cukuplah dengan satu istri (yang sudah ada) saja, atau (cukuplah melakukan hubungan sek dengan) budak-budak yang kamu miliki. Yang demikian itu adalah lebih dekat untuk tidak berbuat aniaya". [an-nisa' [4], 3]

Dalam ayat lain Allah berfirman:

"Perempuan-perempuanmu adalah ladang bagimu, maka datangilah ladangmu dari arah mana dan cara apapun yang kamu sukai .. (al-baqarah [2], 223)

Sedangkan, menurut wikipedia, lesbian adalah istilah bagi perempuan yang mengarahkan orientasi seksualnya kepada sesama perempuan. Istilah ini juga merujuk kepada perempuan yang mencintai perempuan baik secara fisik, seksual, emosional, atau secara spiritual.

Sedangkan Gay adalah sebuah istilah yang umumnya digunakan untuk merujuk orang homoseksual atau sifat-sifat homoseksual. Ada juga yang memaknai gay adalah kecendurangan seorang lelaki yang mempunyai ketertarikan seksual terhadap kaum sejenisnya. Gay juga membawa pengertian yang lebih kurang sama dengan lesbian yaitu penyimpangan pemuasaan seksualitas yang berbeda dengan khalayak ramai (di luar kebiasaan manusia normal), misalnya dengan menjadikan dubur sebagai objek seksualitasnya akan tetapi gejala gay ini dipraktikkan (pemuasannya dilakukan) diantara lelaki dan lelaki. Ada sebagian orang tidak mengenal istilah gay tapi lebiih mengenal penggunaan bahasa perkataan 'liwat'. Sedikit berbeda dengan bisexual, biseksual (bisexual) adalah individu yang dapat menikmati hubungan emosional dan seksual dengan orang dari kedua jenis kelamin baik pria ataupun wanita (kamuskesehatan.com). Lalu bagaimana dengan Transgender? Masih menurut wikipedia, transgender merupakan ketidaksamaan identitas gender seseorang terhadap jenis kelamin yang ditunjuk kepada dirinya. Seseorang yang transgender dapat mengidentifikasi dirinya sebagai seorang heteroseksual, homoseksual, biseksual maupun aseksual.

Dari semua definisi di atas walaupun berbeda dari sisi pemenuhan seksualnya, akan tetapi kesamaanya adalah mereka memiliki kesenangan baik secara psikis ataupun biologis dan orientasi seksual bukan saja dengan lawan jenis akan tetapi bisa juga dengan sesama jenis. Bagaimana jadinya jika naluri melestarikan keturunan ini akan terwujud dengan hubungan sesama jenis? Dari sini jelas sekali bahwa LGBT bertentangan dengan fitrah manusia.

Fenomena Lesbian, Gay, Bisexual dan Transgender (LGBT) merupakan penyimpangan orientasi seksual yang bertentangan dengan fitrah manusia, agama dan adat masyarakat Indonesia. Sebab, Indonesia walaupun bukan negara Islam, namun masih berpegang teguh pada adat ketimuran (easternisasi).

Tidak bisa dipungkiri lagi bahwa saat ini jumlah kelompok homoseksual, baik lesbian atau gay, semakin berkembang. Seperti diungkapkan oleh Dr. Dede Oetomo (2009) yang merupakan Ketua GaYa Nusantara, salah satu organisasi gay terbesar di Indonesia, data statistic menunjukkan 8-10 juta populasi pria Indonesia pada suatu waktu terlibat.

\section{HAM dan Pancasila}

Secara simple HAM (Hak Asasi Manusia) adalah sebagai hak-hak moral fundamental dalam diri manusia yang penting untuk kelangsungan hidupnya (fundamental buman rights of the person that are 
necessary for a life with human dignity). ${ }^{1}$ Hak asasi seringkali dikaitkan dengan hak-hak yang secara natural ada dalam diri setiap manuisa namun, menurut Jeremy Bentham definisi ini kurang spesifik. Selanjutnya, John Locke mendefinisikan hak asasi manusia sebagai hak-hak moral yang tidak dapat dilampaui oleh otoritas publik. Setiap individu adalah pribadi yang sama dan mandiri, yang memiliki hak mendahului keberadaan hukum nasional dan internasional ada (predate national and international law). Sedangkan keberadaan otoritas publik berfungsi untuk menjaga hak-hak pribadi ini dalam kerangka legal. ${ }^{2}$

Dalam masyarakat tradisional, kekuasaan raja bersifat absolut. Ia memiliki kekuasaan besar terhadap individu. Individu harus mengabdi kepada kekuasaan dan dengan ketaatan kepada kekuasaan itulah dia mendapat perlindungan. Apabila individu membahayakan kekuasaan, dia dapat dieliminasi sebagai perlindungan terhadap kekuasaan yang mengklaim diri sebagai pengejawantahan kepentingan kolektif. ${ }^{3}$ Oleh karena itu, subjek utama masyarakat internasional secara tradisional adalah negara. Negara merupakan institusi yang mampu mempresentasikan diri sebagai anggota masyarakat internasional Pengertian ini menunjukkan bahwa kebebasan individual akan selalu dibatasi oleh aturan sosial lokal. Hak individual tidak boleh mendahului hak sosial. Sehingga, HAM baik yang bersifat individual maupun sosial dalam konteks ini susah diberlakukan karena dianggap bertentangan dengan aturan kekuasaan kerajaan.

Bassam Tibi menyatakan bahwa HAM adalah hak-hak individu yang lahir dari pemikiran modern Eropa mengenai hukum alam (natural law). Hak-hak tersebut diangkat oleh negara-negara Eropa sebagai standar institusi hukum. Dari situlah Deklarasi Universal mengenai Hak-hak Asasi Manusia (DUHAM) PBB pada tahun 1948 berasal, dan HAM menjadi hukum Internasional. ${ }^{4}$ Seperti kasus LGBT, di Indonesia kaum seperti ini akan selalu dicerca dan dibenci sebab dalam kultur Indonesia adalah abnormal dan melanggar nurma agama dan sosial.

Hanya saja, batasan HAM ini sebenarnya masih debatebel karena, seperti yang dikatakan Chris Brown, "Virtually everything encompassed by the notion of 'buman rights' is the subject of controversy". Hak-hak asasi manusia ini dikatakan harus dihormati oleh otoritas publik, dituangkan dalam bentuk hukum dan dipertahankan melalui persidangan independen. ${ }^{5}$

Pemerintah Indonesia tentunya tidak ingin serta merta merubah tujuan Negara ini. apalagi mengenai kultur ketimuran dan nilai-nilai tradisional dalam keluarga di negeri ini. Dengan demikian, kita sebenarnya bisa mengatakan bahwa pembentukan undang-undang ini adalah upaya pemerintah Indonesia untuk terlibat dalam pembentukan identitas masyarakatnya, yaitu supaya tidak mengarah pada disorientasi seksual dan hal itu diwujudkan melalui pembatasan informasi terhadap hal-hal yang mengarah pada disorientasi seksual bagi kalangan muda. Oleh sebab itu, Indonesia melalui Ketua MK (Mahkamah Konstitusi) Patrialis Akbar melalui dalam sidangnya menegaskan bahwa Negara Indonesia bukanlah negara sekuler. hlm. 3 .

${ }^{1}$ David P. Forsythe, Human Rights and International Relations, (Cambridge: Cambridge University Press, 2000),

2 Ibid, hlm. 28-19

${ }^{3}$ Islamica, Volume 10, 202 Nomor 1, September 2015

4 Bassam Tibi, "Islamic Law/Syariah and Human Rights: International Law and International Relations" dalam Tori Lindholm and Kari Vogt (eds.), Islamic Law Reform and Human Rights: Challenges and Rejoinders (Oslo: Nordic Human Rights Publications, 1993), hlm 75.

${ }^{5}$ Chris Brown, "Universal Human Rights: A Critique” dalam Dunne dan Wheeler, ed., Human Rights in Global Politics, (Cambridge: Cambridge University Press, 1999), hlm. 103 
Sebagaimana perkataan lengkapnya. "Sebetulnya memang agak berbeda perspektif HAM Indonesia dengan yang ada di Declaration of Human Rights. Ada yang sama tapi ada yang sangat istimewa dan tidak sama dengan negara lain. Kebebasan HAM di negara kita ada pembatasan, dibatasi tidak boleh melanggar HAM orang lain. Kedua, kebebasan dibatasi nilainilai moral. Kemudian dibatasi nilai-nilai agama. Nilai agama ini yang tidak dimiliki oleh Declaration of Human Rights," kata Patrialis dalam sidang di Gedung MK..

Jika kita mengakui LGBT tentu kita menentang agama kita., sebab 6 agama resmi yang ada di negeri ini sepakat bahwa LGBT bertentangan dengan norma agama. Begitu juga, jika LGBT dilegalkan di Indonesia, berarti bertentangan asas Pancasila dan UUD 45. Kebebasan akan selalu dibatasi oleh aturan agama dan Negara dan aturan itu sifatnya memaksa, sehingga siapapun tidak boleh melanggarnya. Oleh sebab itu, Patrialis Akbar mengatakan, "Kita sangat berbeda, karena kita bukan negara sekuler. Negara ini mengakui agama. Kebebasan itu dibatasi nilai-nilai keamanan dan ketertiban. Melihat satu masalah tidak boleh hanya dari satu perspektif. Kalau hanya dilihat perspektif HAM, harus kita perdebatkan. Apakah melakukan pencabulan, perzinaan, dibenarkan HAM. Harus komprehensif," dalam pandangan beliau. Dengan demikian setiap negara memiliki standar HAM tertentu yang pastinya akan sangat berbeda dengan Negara lain.

Negara Indonesia memiliki standar hukum Negara. Standar hukum ini termaktub UUD 45 dan Pancasila. Ide maupun konsep negara hukum pada umumnya dimaksudkan dalam rangka menghinadari negara atau pemerintah dari perbuatan sewenang-wenang dan melewati batas olehn warganya. Karena bagaimanapun, bahwa suatu pemerintahan yang tidak dikontrol dengan perangkat hukum yang tegas dan konkrit akan sangat rentan dengan berbagai bentuk penyimpangan dan penyalahgunaan kekuasaan. Bahkan pada era modern sekarang, dapat dikatakan bahwa merupakan suatu negara yang sangat relevan dan ideal bila kemudian segala rangkaian kegiatan kenegaraannya didasarkan pada mekanisme hukum yang jelas dan tegas. ${ }^{2}$

Di sisi lain, pembentukan identitas wewenang dan tindakan seseorang melibatkan dua dimensi lingkungan: internal dan eksternal. Dalam hal lingkungan eksternal, informasi sebagai sumber pengetahuan bagi individu merupakan bagian dari faktor eksternal yang sangat berpengaruh terhadap pembentukan identitas individu. Dari sudut pandang HAM, akses terhadap infomasi adalah bagian dari hak asasi. Dengan demikian, ada hubungan yang erat antara informasi dan pembentukan identitas dengan hak asasi manusia.

Indonesia yang sumber hukum utamanya adalah Pancasila, maka setiap perkara apapun harus dikembalikan pada sumber hukum Negara ini. Jika bertentangan maka harus dibuang jauhjauh. Walau Indonesia tidak secara tegas dan jelas Negara Indonesia adalah Negara agama, hanya saja jika kita kembali ke butir-butir Pancasila, maka akan kita temukan secara implisit bahwa Negara Indonesia adalah Negara beragama. Sehingga, apa saja yang bertentangan dengan Negara dan agama harus ditolak.

Sebab secara hermeneutis, The founding fathers, Soekarno dalam peroses perumusan Pancasila terutama sila ketuhanan yang maha esa ini penting untuk ditemukan esensinya, karena

${ }^{1}$ Disadur dari detik.com hari selasa tanggal 23-08-2016 pada sidang gugatan sidang yang digelar atas gugatan yang dimohonkan Guru Besar IPB Bogor Prof Dr Euis Sunarti, Rita Hendrawaty Soebagio SpPsi MSi, Dr Dinar Dewi Kania, Dr Sitaresmi Sulistyawati Soekanto, Nurul Hidayati Kusumahastuti Ubaya SS MA, dan Dr Sabriaty Aziz. Ada juga Fithra Faisal Hastiadi SE MA MSc PhD, Dr Tiar Anwar Bachtiar SS MHum, Sri Vira Chandra D SS MA, Qurrata Ayuni SH, Akmal ST MPdI dan Dhona El Furqon SHI MH yang bertempat di Jalan Medan Merdeka Barat, Jakarta Pusat, Selasa (23/8/2016)

2 Disadur dari Jurnal Dinamika Hukum Vol. 14 No. 3 September 2014 pada tanggal 16-10-2016 
pada hakikat sila pertama inilah Negara Indonesia meletakan basis filosofis Negara yang khas dan tidak sepadan dengan filsafat Negara yang lain di dunia. Sebagaimana dikemukan oleh Kahin dan Dahm bahwa perumusan pancasila yang dikemukakan oleh Soekarno merupakan konsepsi yang khas yang tidak ada pada pemikiran filsafat negara yang lain di dunia. Walau ada yang berpendapat bahwa pemikiran Soekarno itu merupakan suatu sintesis dari demokrasi barat, Islamisme dan Marxisme. Namun demikian sebenarnya banyak pandangan dan masukan dalam proses perumusan sila ketuhanan Yang Maha Esa, terutama dalam hubungan dengan hubungan Negara dengan agama dalam Negara Indonesia yang akan didirikan. ${ }^{1}$

\section{Sila Pertama Pancasila}

Ideologi Pancasila merupakan sumber dasar pembentukan Negara Kesatuan Republik Indonesia (NKRI). Fungsi Pancasila sebagai sumber primer dalam membatasi gerak gerik masyarakat Indonesia agar aman dan tertib. Hal ini berarti bahwa moral Pancasila telah menjadi sumber tertib negara dan sumber tertib hukumnya, serta jiwa seluruh kegiatan negara dalam segala bidang kehidupan. Pancasila pun harus dijadikan warisan turun temurun kepada generasi muda bangsa Indonesia berikutnya melalui pendidikan keindonesiaan dan kebangsaan. Setiap bangsa memiliki identitas yang khas yang tertuang dalam flsafah negaranya. Sebagai bangsa yang besar, kepedulian kepada pewarisan budaya luhur bangsanya harus selalu dijaga dan disosialisasikan.

Indonesia memiliki hukum yang jelas dan tegas yang tersirat dalam Pancasila, tetapi karena pengamalan yang masih sangat kurang bahkan dikhawatirkan akan dapat dipengaruhi oeh asimilasi kultural asing (LGBT). Di samping itu kita khawatir adanya tafsiran parsial dan kesukuan yang dapat saja memaksakan dan melumpuhkan persatuan dan kesatuan bangsa. Contohnya, kita memiliki tradisi musyawarah untuk mufakat tetapi semakin langka penerapannya. Kita memiliki iklim dekmoratis dalam kehidupan nasional, tetapi tuntutan demi tuntutan untuk menciptakan iklim demokratis telah mengundang pertanyaan yaitu kemurnian dari sikap demokratisnya tersebut

Sejak awal pertama disahkan secara konstitusional pada tanggal 18 agustus 1945, Pancasila dapat dikatakan sebagai dasar (falsafah) Negara, sumber hukum utama, pandangan hidup, ideologi nasional dan ligatur pemersatu dalam peri keaagamaan, peri kehidupan dan kebangsaan dan kenegaraan Indonesia. Singkat kata Pancasila adalah dasar pokok yang mempersatukan sekaligus bintang penuntun (leitstar) yang dinamis, yang mengarahkan bangsa dalam mencapai tujuannya. Dalam posisinya seperti itu, Pancasila merupakan sumber jati diri, keperibadian sumber moralitas, dan haluan keselamatan bangsa. ${ }^{2}$

Dari berbagai macam kedudukan dan multi fungsi Pancasila sebagai titik sentral pembahasan adalah kedudukan dan fungsi pancasila sebagai dasar Negara republik Indonesia, hal ini sesuai dengan kausa finalis pancasila yang dirumuskan oleh pembentuk Negara pada hakikatnya adalah sebagai dasar Negara republik Indonesia, adalah digali dari unsur-unsur yang berupa nilainiai yang terdapat pada bangsa Indonesia sendiri yang berupa pandangan hidup bangsa Indonesia sendiri. Oleh karena itu dari berbagai macam kedudukan dan fungsi pancasila sebenanya dapat dikembalikan pada dua macam kedudukan dan fungsi pancasila yang pokok yaitu sebagai dasar Negara republik Indonesia dan sebagai pandangan hidup bangsa Indonesia. Namun yang

1 Tijani Abd.Qadir Hamid, Pemikiran Politik Dalam Al-Qur'an, Cetakan Pertama, (Jakarta: Gema Insane Press, 2001) hlm 57

2 Yudi latif, Negara Paripurna Historis, Rasionalitas, Dan Aktualitas Pancasila, Cetakan Keempat, (Jakarta: PT Gramedia, 2012), hlm 40-41 
terpenting bagi kajian ilmiah adalah bagaimana hubungan secara kausalitas diantara kedudukan dan fungsi pancasila yang bermacam-macam tersebut. ${ }^{1}$

Oleh karena itu, perlu ada upaya pewarisan budaya penting tersebut melalui pendidikan Pancasila yang dilaksanakan dalam pendidikan formal (sekolah). Sebagai dasar negara, Pancasila memiliki kekuatan mengikat secara yuridis. Seluruh tatanan kehidupan berbangsa dan bernegara yang bertentangan dengan Pancasila sebagai kaidah yuridis-konstitusional pada dasarnya tidak berlaku dan harus dicabut dan dihapus. Dengan demikian penetapan Pancasila sebagai dasar falsafah negara berarti bahwa moral bangsa telah menjadi moral Negara berasakan agama yang termaktub dalam Pancasila.

Unsur pembentukan Pancasila berasal dari bangsa Indonesia sendiri. Sejarah Indonesia membuktikan bahwa nilai luhur keberagaman dalam berbangsa yang tercipta merupakan sebuah kekayaan yang dimiliki dan tidak bisa tertandingi oleh falsafah Negara manapun sehingga hans tetap terjaga. Di Indonesia tidak pernah putus-putusnya orang percaya kepada Tuhan, hal tersebut terbukti dengan adanya tempat peribadatan yang dianggap suci, kitap suci dari berbagai ajaran agamanya, upacara keagamaan, pendidikan keagamaan, dan lain-lain merupakan salah satu wujud nilai luhur dari Pancasila khususnya sila ke-1.

Upaya sebagian Ormas untuk melegalkan LGBT di Indonesia tentunya sangat bertentangan dengan norma Pancasila sila pertama. Apabila Pancasila disebut sebagai identitas bangsa dimana Pancasila mampu memberikan satu pertanda atau ciri khas yang melekat dalam tubuh masyarakat terutama dalam sila pertama 'Ketuhanan Yang Maha Esa'. Hal ini yang mendorong bagaimana statement masyarakat mengenai nilai-nilai yang terkandung dalam Pancasila tersebut. Sebagai contoh nilai 'Ketuhanan Yang Maha Esa’ yang bermakna sangat luas dan tidak memihak terhadap satu agama, golongan ataupun individu tertentu. Sehingga setiap prilaku bangsa Indonesia harus berafiliasi dari Pancasila. Prilaku LGBT sangat bertentangan dengan unsur Pancasila.

Hanya saja, sila pertama ini mengisyaratkan bahwa Negara Indonesia adalah Negara beragama. Sebagaimana kita ketahui agama yang diakui oleh Negara ada enam agama, Islam Kristen Katolik, Kristen Protestan, Hindu, Budha dan Konghucu. Dari enam agama yang diakui ini, tidak satu agama pun dalam kitab sucinya yang melegalkan LGBT. Sehingga, jika ada pihak yang berwacana melegalkan LGBT, selain akan bertentangan dengan agama, juga yang tidak kalah pentingnya akan sangat bertentangan dengan sumber hukum Negara yakni Pancasila. Jika tetap dipaksakan, maka tidak menutup kemungkinan akan ada konflik sosial. Oleh sebab itu perlu kiranya penerapan butir Pancasila secara komprehensif dan sistematis dalam mengaturnya.

Apalagi, mayoritas rakyat Indonesia beragama Islam. Tetapi, walau muslim Indonesia mayoritas, tetap dengan legowo umat Islam menerima Pancasila yang memang dianggap di dalam butir-butirnya mengandung nilai-nilai keIslaman. Perbedaan agama atau keyakinan tidak boleh dijadikan alasan untuk mendiskriminasikan seseorang karena persolalan agama dan keyakinan adalah persoalan hidayah. Salah satu perinsip keadilan adalah tidak memperlakukan diri sendiri atas seseorang berdasarkan garis nasab, darah. ${ }^{2}$

${ }^{1}$ Kaelan, Negara Kebangsaan Pancasila, Kultur, Historis, Filosofis, Yuridis, Dan Aktualisasinya, cetakan pertama (Yogyakarta, paradigm, 2013), hlm 40-41

2 Masdar Farid Mas"Udi, Syarah UUD 1945 Perspektif Islam, cetakan ketiga, ( Jakarta: PT pustaka alvabert, 2013), hlm 53 
Sedang di dalam keyakinan umat sangat jelas apa huku hukum kaum LGBT ini Sebagaimana Firman Allah SWT yang menamakan perbuatan ini dengan perbuatan yang keji (fahisy) dan melampui batas (musrifun). Sebagaimana Allah terangkan dalam al Quran:

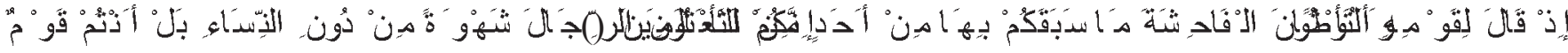
مُسْرِ قُونْ

"Dan (Kami juga telah mengutus) Luth (kepada kaumnya). (Ingatlah) tatkala dia berkata kepada mereka: "Mengapa kamu mengerjakan perbuatan faahisyahI(keji) itu, yang belum pernah dikerjakan oleh seorangpun (di dunia ini) sebelummu. Sesungguhnya kamu mendatangi lelaki untuk melampiaskan nafsumu (kepada mereka), bukan kepada wanita, bahkan kamu ini adalah kaum yang melampaui batas.” (TQS. Al 'Araf: 80-81)

Kaum LGBT Liwath (gay) dan Sihaaq (lesbian) adalah perbuatan yang dilakukan oleh lakilaki dengan cara memasukan dzakar (penis)nya kedalam dubur laki-laki lain. Kaum Liwath adalah suatu kata (penamaan) yang identik dengan kaumnya Luth a.s karena kaum Nabi Luth a.s adalah kaum yang pertama kali melakukan perbuatan ini. Kemudian dalam sejarah, kaum Nabi Luth a.s yang telah melakukan sodomi dikenal dengan sebutan kaum Sodom atau bangsa Sodom. ${ }^{1}$

Sedang kaum Sihaaq (lesbian) adalah hubungan cinta birahi antara sesama wanita dengan image dua orang wanita saling menggesek-gesekkan anggota tubuh (farji')nya antara satu dengan yang lainnya, hingga keduanya merasakan kelezatan dalam berhubungan tersebut (Sayyid Sabiq, Fiqhu as-Sunnah, Juz 4/hal. 51). Tentu perbuatan keduanya ini menyimpang dari nurma agama dan Negara Indonesia yang mana dalam pemaknaan pernikahan adalah dua pasangan berbeda jenis yang saling suka dan ingin menghasilkan keturunan.

Agama lain seperti Kristen Katolik misalnya, juga menolak LGBT, dalam Kitab Hukum Kanonik (KHK) 1983, kanon 1055 berbunyi “ Perjanjian perkawinan, dengan mana pria dan perempuan membentuk antar mereka kebersamaan seluruh hidup, dari sifat kodratinya terarah pada kesejahteraan suami-istri serta pada kelahiran dan pendidikan anak; oleh Kristus Tuhan perkawinan antara orang-orang yang dibaptis diangkat ke martabat sakramen. Sedang triologi Pernikahan Kristiani: Pernikahan dibangun atas prinsip monogami (satu dengan satu), ikatan heteroseksual (laki-laki dengan perempuan), dan komitmen seumur hidup bukan kontrak. Bahkan, dalam agama Yahudi dijelaskan keharaman homoseksual yang yang termaktuk dalam kitab mereka Levaticus 18:22 dan 20:13. ${ }^{2}$

Walaupun ada sebagian kelompok LGBT mengklaim keberadaannya karena faktor genetis dengan teori “Gay Gene” yang pernah diusung oleh Dean Hamer pada tahun 1993. Akan tetapi, teori yang digagasnya, oleh Dean, sebagai seorang gay kemudian meruntuhkan sendiri hasil risetnya tersebut. Dean mengakui risetnya itu tak mendukung bahwa gen adalah faktor utama/yang menentukan yang melahirkan homoseksualitas. Perbuatan LGBT sendiri ditolak oleh semua agama bahkan dianggap sebagai perbuatan yang menjijikan, tindakan bejat, dan keji. ${ }^{3}$

\section{Tafsiran Sila Ke 2}

Dari kata-kata „manusia’ kemanusiaan adalah sesuatu yang terkait dengan hakikat manusia, apa dan siapanya. Yang hendak ditegaskan dengan perinsip kemanusiaan ini (sila kedua pancasila)

\footnotetext{
1 (Huk.mu al-liwath wa al-Sihaaq, hlm. 1).

${ }^{2}$ Jeefrey S. Siker, "Homosexuality and Religion an Encyclopediaq. Dalam buku ini mayoritas semua agama tentang LGBT.

${ }^{3}$ Republika.co.id, 26/01/2016
} 
adalah bahwa hakikat dan martabatnya manusialah yang harus dijadikan acuan moral dalam merumuskan dan menjalankan kebijakan-kebijakan berbangsa dan bernegara indonesia. Tentang hal ini, Wahbah Zuhaili menulis: Kemuliaan manusia adalah hak kodrati setiap insan yang di lindungi oleh Islam sebagai landasan etika dan tata pergaulan, tak seorangpun boleh dilecehkan hak-haknya, ditumpahkan darahnya atau direndahkan martabatnya secara begitu saja; tidak peduli apakah dia orang yang dianggap baik atau buruk, beragama Islam atau non muslim.

Kemanusiaan yang dimaksud dalam pancasila adalah kemanusiaan yang adil pada diri sendiri, terhadap sesama, dan terhadap Tuhan. Karena itu kemanusiaan yang adil dan beradab mengandung prinsip perikemanusiaan atau internasionalisme yang terjelma dalam hubungan baik antar manusia, antar bangsa, tanpa terjebak dalam ego kesukuan sempit. Sementara yang dimaksud dengan beradab adalah martabat manusia yang dijunjung setinggi-tingginya. Sehingga penjabaran sila kemanusiaan adalah mengakui persamaan derajat manusia serta hak dan kewajibannya di antara sesama, saling mencintai, mengembangkan sikap tenggang rasa, tidak semenamena terhadap orang lain, menjunjung tinggi nilai-nilai kemanusiaan, berani membela kebenaran dan keadilan, memandang diri sebagai bagian umat manusia yang konsekuensinya adalah mengembangkan kerja sama dengan bangsa-bangsa lain dan saling menghormati.

Dalam pandangan penulis, Pancasila merupakan representasi dari nilainilai keagamaan dalam rangka menghormati harkat dan martabat manusia tanpa membedakan ras, agama, kepercayaan dan budaya. Nyawa manusia itu sakral dan tak bisa dilanggar dan setiap usaha harus di buat untuk melindungi keselamatannya.Islam memberikan kebebasan kepada umat manusia untuk berserikat menjalin persahabatan dan kerjasama dengan siapa pun, tanpa paksaan dari pihak lain, setiap orang berhak diperlakukan sesuai dengan hukum, dan hanya sesuai dengan hukum, setiap orang berhak dan berkewajiban untuk membela hak-hak orang lain dan hak-hak komunitas secara umum, dalam membela hak-hak pribadi maupun publik, setiap orang tidak boleh diskriminasikan[23]. Dengan demikian, memuliakan manusia, sebagai gambar Allah dan khalifahnya pada hakikatnya adalah memuliakan Allah, tuhan yang maha esa Pun sebaliknya, menghinakan manusia dan kemanusiaan adalah penghinaan kepada Allah Swt. Dalam hidup berbangsa dan bernegara Indonesia, dengan alasan apapun, tidak boleh terjadi pelecehan terhadap harkat dan martabat manusia indonesia karena nantinya akan bertabrakan dengan Pancasila.

\section{PENUTUP}

Pancasila sebagai dasar Negara Indonesia. Saat Ir. Soekarno menetapkan sebagai dasar Negara tentu banyak pertimbangan di dalamnya, yang kemudian terkandung lah lima nilai falsafah yang tertuang didalamnya kemudian dikenal dengan Pancasila. Tentu sudah memenuhi keriteria dan keinginan Rakyat Indonesia bahkan ajaran Islam yang notabene-nya pemeluk agama terbesar di negeri ini beragama Islam. Pancasila, dengan begitu banyak suku, bahasa, budaya dan agama, Pancasila mampu mengakomodir semunya dalam satu bingkai persatuan, ini menandakan Negara kita memiliki dasar yang agamis karena semuanya itu masuk pada ajaran Islam dan agama lainnya. Karena sebenarnya ajaran Islam dan non Islam sangat menghargai perbedaan menjunjung tinggi keadilan dan sangat terbuka.

Berkaitan dengan hukum Internasional atau Hak Asasi Manusia (HAM), maka Indonesia memiliki batasan tertentu berkaitan dengan HAM. Tidak serta merta HAM masuk ke Indonesia kemudian langsung diterima. Pancasila dan UUD 45 akan selalu menjadi benteng penghalang

\footnotetext{
${ }^{1}$ Wahbah Zuhaili, al-figh al-islami wa Adillatuh, jilid VI, (Beirut: Dar al-Fikr. 2004), hlm. 70
} 
setiap budaya dan tradisi barat masuk ke Indonesia apalagi produk barat tersebut bertentangan dengan nilai-nilai pancasila. Dan, LGBT adalah bagian dari produk barat yang ditolak.

Berkaitan dengan kaum LGBT yang sedang hangat diperbincangkan, tentunya kita sebagai warga negara yang baik dan taat pada aturan pemerintah, maka harus mengikuti apa yang ditetapkan kepada kita. LGBT sebagaimana penulis jelaskan di atas, sangat bertentangan dengan norma-norma Pancasila dan UUD 45 yang menjadi sumber hukum utama bagi negeri ini. Maka harus ditolak bersama. Pancasila sebagai representasi dari negara yang di dalamnya telah mengandung norma-norma agama yang sudah tidak sejalan dengan tujuan dan keinginan kaum LGBT. Membiarkan LGBT berkembang berarti telah membuat bibit pertikaian dalam masyarakat Indonesia, sehingga, sebelum terjadi anarkis dan kekerasan, maka pemerintah bersama masyarakat harus menghalau adanya propaganda LGBT yang masuk ke Indonesia.

Namun, seiring berjalannya waktu, hukum Internasional (red-HAM) yang ingin mengatur suatu Negara yang sah. HAM dianggap solusi bagi setiap permasalahan yang dianggap tidak bisa diselesaikan oleh Negara terutama hal-hal yang berkaitan dengan hak-hak kaum LGBT. Namun dalam realitas di antara HAM dan Negara (Indonesia) yang dituju, seringkali tidak sejalan. Oleh karena itu LGBT harus tetap ditolak.

Dari berbagai wacana dan usaha melegalkan LGBT, maka sikap masyarakat Indonesia setidak ada lima tanggapan:

1. Hukum Internasional (HAM) sering berseberangan dengan Pancasila sehingga dianggap tidak sesuai dengan cita-cita pendiri bangsa jika tetap diberlakukan. Jadi, penolakan Pancasila terhadap LGBT sepenuhnya tidak bertentangan dengan HAM, sebab setiap negara memiliki batas-batas tertentu tentang penerapan HAM.

2. HAM hanya dapat direalisasikan di bawah hukum Pancasila dan UUD 45 sebab keduanya ini adalah bagian dari peng-ngontrol perbuatan manusia Indonesia. Sedang LGBT sebagai produk HAM sangat jauh dari nilai Pancasila, UUD 45 dan karakter bangsa Indonesia.

3. HAM internasional merupakan agenda gaya baru kaum imperialis yang harus ditolak. Salah satunya lewat gerakan LGBT

4. HAM internasional tidak sesuai dengan nilai-nilai Pancasilais yang agamis.

5. Tujuan HAM internasional memiliki agenda tersembunyi, yakni antiagama.

6. Bangsa Indonesia yang Agamis tetap menjunjung tingga nilai kemanusiaan sehingga harus tetap menjaga keamanan dan kestabilan bangsa dalam menghalang kaum LGBT.

Jika demikian, LGBT sangat membahayakan untuk kesetabilan negara indonesia maka pemerintah harus benar-benar memikirkan persoalan ini agar ada solusi terbaik untuk bangsa Indonesia sehingga bisa meredam anarkis masyarakat Indonesia terhadap kaum LGBT.

\section{REFRENSI}

Bassam Tibi, 1993. Islamic Law/Syariah and Human Rights: International Law and International Relations dalam Tori Lindholm and Kari Vogt (eds.), Islamic Law Reform and Human Rights: Challenges and Rejoinders. Oslo: Nordic Human Rights Publications.

Chris Brown, 1999. "Universal Human Rights: A Critique" dalam Dunne dan Wheeler, ed., Human Rights in Global Politics. Cambridge: Cambridge University Press,

David P. Forsythe, 2000. Human Rights and International Relations. Cambridge: Cambridge University Press.

Disadur dariJurnal Dinamika Hukum Vol. 14 No. 3 September 2014 pada tanggal 16-10-2016 
ISLAMICA, Volume 10, 202 Nomor 1, September 2015, dengan LGBT dalam Perspektif Islam

JURNAL LISAN AL-HAL Volume 4, "No. 2, Desember 2012"

Kaelan, 2013. Negara Kebangsaan Pancasila, Kultur, Historis, Filosofis, Yuridis, Dan Aktualisasinya, Cetakan Pertama. Yogyakarta: paradigma.

Masdar Farid MaseeUdi. 2013. Syarah UUD 1945 Perspektif Islam, Cetakan Ketiga. Jakarta: PT Pustaka Alvabert.

Republika.co.id, 26/01/201

Rida, Rashid. 1950. Tafsìr al-Qur'an al-Karim, al-Mushtabìr biTafsìr al-Manar, Juz ix. Kairo: Matba'ah Hajari,

Sabiq, Sayyid. 1968. Fiqh al-Sunnah. Libanon: Dār al-Fikr.

Shalthut, Mahmud. 1968. al-Islam Aqüdatun wa Sharr'atun. Mesir: Dār al-Qalam.

Soemiyati, 1999. Hukum Perkawinan Islam dan Undang-Undang Perkawinan, Cet. Ke-4. Yogyakarta : Liberti,

Subekti,dkk. 1996. Kitab Undang-undang Hukum Perdata. Cet. ke-28. Jakarta : Pradaya Paramita.

Sudirman, Rahmat. 1999. Konstruksi Seksualitas Islam Dalam Wacana Sosial; Peralihan Tafsir Seksualitas. Cet. ke-1. Yogyakarta : Media Pressindo.

Tijani Abd.Qadir Hamid. 2001. Pemikiran Politik. Dalam Al-Qur'an, Cetakan Pertama. Jakarta: Gema Insane Press.

Wahbah zuhaili, 2004. al-figh al-Islami wa Adillatuh. Jilid VI. Beirut : Dar al-Fikr.

Wahhāb Khallāf . Abd. Ilmu Ushūl al-Fiqh, Haramain: Linnashr wa al-Tauż̀̀u, 2004.

www.detik.com $(23 / 8 / 2016)$

Yakan, 1989. Fathi al-Islam wa al-Jins, penerj. Syafril Halim, Islam dan Seks.Jakarta: Al-Hidayah.

Yudi latif. 2002. Negara Paripurna Historis, Rasionalitas, dan Aktualitas Pancasila. Cetakan Keempat. Jakarta: PT Gramedia.

Zuhdi, Masjfuk. 1996. Masail Fighiyah.Jakarta : Toko Gunung agung.

Zunli Nadia. 2005. Waria Laknat atau Kodrat. Yogyakarta: Pustaka Marwa, 2005.

54 RAHEEMA: J urnal Studi Gender dan Anak 